\title{
PERANCANGAN SISTEM INFORMASI HARGA POKOK PRODUKSI DENGAN METODE BIAYA ACTIVITY BASED COST SYSTEM PADA PT. ASELI DAGADU DJOGDJA
}

\author{
Dinik Fitri Rahajeng Pangestuti \\ STIKES Surya Global \\ din_fitri@yahoo.com
}

\begin{abstract}
Rapid development of information technology and business realizes companies to put information as the major need. A good information system will help decision maker to run their duties faster, more quickly and more accurately. A good accounting information system can be used also to arrange the using of economical resaources had by companies to be more efficient and effective. In manufacture industries, have many varieties costing method to apply. ABC System is one of the costing calculation alternative which is relatively proper for manufacture industries having a relatively high diversity of product. Thus, to implement ABC system in manufacture industries will be complicate, in order it needs a tool to support the decision. Designing information system will give solution to the problem. This research use FAST (Framework for the Application of System Thinking) methodology promoted by Bentley and Whitten in their book title is System Analysis and Design for Global Enterprises to design production information system. By designing production information system will give information of cost of goods manufactured with ABC System approach and another important thing to help in the making desicion and give the optimal serving to customer.
\end{abstract}

Keyword: Information technology, manufacture industry, ABC System, production information design.

\section{PENDAHULUAN}

Perkembangan teknologi informasi dan bisnis yang pesat dalam era globalisasi menyadarkan perusahaan untuk menempatkan informasi sebagai kebutuhan yang utama. Sistem informasi yang baik akan membantu para pembuat keputusan untuk melakukan tugasnya dengan lebih cepat, tepat dan akurat. Sistem Informasi Akuntansi yang baik juga dapat untuk mengatur penggunaan sumber daya ekonomi yang dimiliki perusahaan secara lebih efisien dan efektif. Penelitian ini berjudul "Usulan Rancangan Sistem
Informasi Produksi untuk Menghitung Cost of Goods Manufacturing dengan Pendekatan Biaya ABC System, Studi Kasus pada PT. Aseli Dagadu Djokdja”. Pertimbangan dalam pemilihan judul tersebut didasarkan pada pentingnya teknologi informasi dalam mendukung kegiatan operasi perusahaan, khususnya sistem informasi produksi. Hal ini disebabkan bagian paling rumit dan krusial dalam industri manufaktur adalah pada siklus produksi, karena dari situlah perusahaan menghasilkan produk untuk dijual serta terjadi transformasi dari bahan baku menjadi barang jadi, sehingga banyak proses yang turut berperan, 
yang menimbulkan cost tambahan. Perancangan sistem dan metode penentuan harga pokok produksi yang baik dapat membantu kelancaran operasi bisnis dan akurasi informasi.

Penelitian ini bertujuan untuk memberikan alternatif solusi terhadap permasalahan yang dihadapi PT. Aseli Dagadu Djokdja dalam meningkatkan kualitas laporan dengan mendesain rancangan sistem informasi. Mengingat sistem informasi mempunyai banyak macamnya maka di dalam penelitian ini hanya dibahas halhal yang berkaitan dengan sistem informasi produksi dengan Activity Based Costing. Hal ini disebabkan karena terbatasnya waktu dan biaya, sehingga dipilih bagian yang menurut hasil observasi paling membutuhkan perhatian.

Ruang lingkup penelitian atau objek dalam penelitian ini adalah PT. Aseli Dagadu Djokdja yang dilakukan pada bulan Januari sampai dengan Maret 2015. Alasan dipilihnya perusahaan tersebut sebagai objek penelitian adalah karena keadaan perusahaan sesuai permasalahan yang diteliti dan data yang diperlukan penulis dalam penelitian ini dapat diperoleh dari perusahaan ini. Dengan adanya penelitian ini diharapkan dapat:

1. Memberikan sebuah gambaran mengenai metode costing yang sesuai dengan kondisi dan kebutuhan perusahaan.

2. Hal-hal apa yang perlu dibenahi untuk menghasilkan sebuah informasi yang memiliki integritas, cepat, tepat dan akurat.

3. Hal-hal yang mana yang harus ditingkatkan dan dipertahankan berdasarkan dari hasil penelitian yang diperoleh.

\section{REVIEW LITERATUR DAN HIPOTESIS}

\section{Definisi Activity Based Cost (ABC) System}

Definisi ABC System menurut Turney
dalam Mulyadi (1999) adalah metode
penghitungan biaya dan kinerja aktivitas
serta penghitungan biaya dan objek biaya.

Penghitungan biaya dilakukan berdasarkan aktivitas yang digunakan sebagai sumberdayanya serta menghitung biaya berdasarkan objek biaya dalam setiap aktivitasnya. ABC System menghitung hubungan sebab akibat antara penggerak biaya dengan aktivitas.

\section{Urgensi Penerapan ABC System}

Persyaratan dasar yang membuat timbulnya pertimbangan diterapkannya $\mathrm{ABC}$ adalah (Hansen dan Mowen, 2005):

1. Nonunit-based cost mempunyai prosentase yang signifikan dalam total overhead cost. Jika jumlah nonunit-based cost ini tidak material, maka pengalokasiannya tidak menjadi masalah.

2. Rasio konsumsi aktivitas dari unit based dan non unit based harus berbeda. Jika produk mengkonsumsi semua overhead activities dengan rasio yang kurang lebih sama maka penggunaan unit-based cost driver sebagai dasar pengalokasian biaya pun tidak menjadi masalah.

\section{Komponen ABC System}

Sebelum menggunakan $A B C$ system, baseline atau starting point diperlukan dalam proses peningkatan bisnis, baseline dapat juga menggambarkan beberapa format model. Baseline adalah dokumentasi organisasi atau kebijakan agen, langkah-langkah praktis, metode, pengukuran, biaya dan hubungan antar bagian pada titik-titik tertentu dalam satu waktu. Melalui proses baselining tersebut, aktivitas input dan output lintas lini dapat dengan mudah diidentifikasi. ABC sistem adalah sebuah metodologi yang menyiapkan output berupa harga produksi per unit. Fungsi penting ABC dalam organisasi adalah memisahkan antara kegiatan yang bernilai tambah (value added activities) dengan kegiatan yang tidak bernilai tambah (non value added activities). 
Value added activities adalah kegiatan yang menyebabkan konsumen tidak berkeberatan untuk membayar aktivitas tersebut dalam pelayanan yang diberikan. Sedangkan non value added activities adalah kegiatan tambahan yang sia-sia serta konsumen tidak bersedia untuk membayar pelayanan tersebut (Hongren, 2006).

\section{Komputerisasi $A B C$ System}

Sistem informasi adalah suatu sistem di dalam suatu organisasi yang mempertemukan kebutuhan pengolahan transaksi harian, mendukung operasi, bersifat manajerial, dan kegiatan strategi dari suatu organisasi dan menyediakan kepada pihak luar tertentu dengan laporan-laporan yang diperlukan (Jogiyanto, 2005). Dalam komputerisasi sistem informasi diperlukan beberapa langkah yaitu:

\section{Pengumpulan Requirement}

Untuk membangun sebuah sistem kita harus dapat mengidentifikasi, menganalisis serta memahami requirement dari sistem yang akan kita bangun tersebut dengan baik dan benar. Proses dan teknik untuk melakukan proses identifikasi, analisis dan pemahaman tersebut dinamakan requirements discovery (Bentley, Whitten, 2007). Menentukan secara spesifik yang harus dilakukan sistem informasi (functional requirements) atau kelengkapan atau kualitas seperti apa yang harus dimiliki oleh sistem (non functional requirements) disebut system requirements.

\section{Teknik Use Case}

Use case diagram didefinisikan sebagai sebuah kumpulan transaksi dan aliran kejadian yang terjadi pada saat pertama kali pemakai mulai menggunakan sistem hingga tujuan dari pemakai tercapai (Bentley, Whitten, 2007).

\section{Data Modeling}

Data modeling merupakan teknik untuk mengorganisir dan mendokumentasikan data yang dimiliki oleh sistem. Data modeling sering disebut database modeling (Bentley, Whitten, 2007) yang digambarkan dalam Entity Relationship Diagram. Simbol yang digunakan dalam database modeling (Entity relationship Diagram) dapat dilihat pada Tabel 1.

\section{Tabel 1}

\section{Simbol Entity Relationship Diagram}

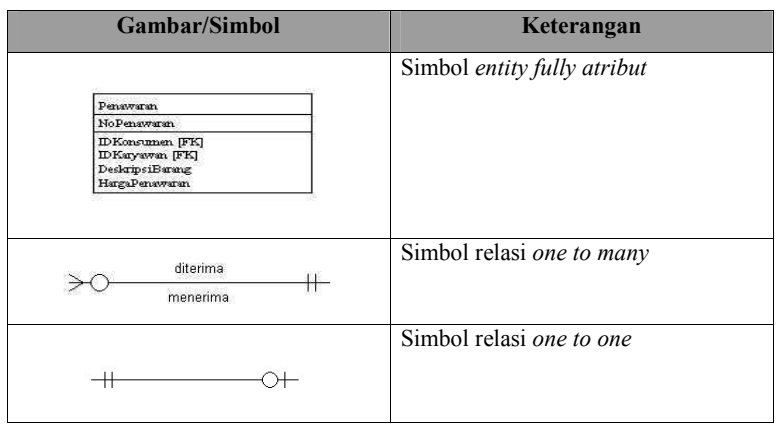

Sumber: Bentley, Whitten (2007)

\section{Process Modeling}

Process modeling merupakan teknik untuk mengorganisir dan mendokumentasikan struktur dan aliran data melalui proses dari sebuah sistem dan atau logika, kebijakan dan prosedur untuk diimplementasikan oleh proses dari suatu sistem (Bentley, Whitten, 2007). Proses tersebut digambarkan dalam sebuah diagram yang disebut Data Flow Diagram (DFD). Simbol yang digunakan dalam DFD menurut Gane \& Sarson dapat dilihat dalam tabel 2. 
Tabel 2

Simbol Data Flow Diagram

\begin{tabular}{|c|c|}
\hline Gambar/Simbol & Keterangan \\
\hline Konsumen. & Simbol external entity \\
\hline \begin{tabular}{c|c|}
\hline $\begin{array}{c}\text { Buat Initial } \\
\text { Desain }\end{array}$ \\
\hline Desain
\end{tabular} & Simbol proses \\
\hline Dosain & Simbol datastore \\
\hline & \\
\hline
\end{tabular}

Sumber: Bentley, Whitten (2007)

\section{Database Design}

Suatu sistem informasi adalah sumberdaya yang menghubungkan antara pengumpulan, manajemen, pengendalian serta penyebaran informasi secara keseluruhan dalam sebuah organisasi (Connolly, 2002). Sistem informasi berbasis komputer memiliki komponenkomponen yaitu: database, database software, application software, computer hardware termasuk media penyimpanan, penggunaan oleh personil dan pengembangan sistem.

\section{Data Dictionary}

Data dictionary adalah spesialisasi aplikasi dari berbagai macam dictionary yang digunakan sebagai referensi dalam hidup seharihari (Kendall, 2002). Data dictionary merupakan referensi kerja dari data tentang data (atau dikenal dengan metadata).

\section{Ancaman-ancaman dan Pengendalian dalam Siklus Produksi}

Dalam siklus produksi ada beberapa ancaman yang dapat mengganggu efektifitas, efisiensi dan reliabititasnya. Romney dan Steinbart (2007) membagi aktivitas produksi menjadi 5 kelompok besar. Masing - masing aktivitas tersebut memiliki ancaman dan prosedur pengendaliannya. Hal tersebut dapat dilihat dalam tabel 3.

Tabel 3

Ancaman-ancaman dan Pengendalian dalam Siklus Produksi

\begin{tabular}{|c|c|c|}
\hline $\begin{array}{l}\text { Process/ } \\
\text { Activity }\end{array}$ & Threat & Applicable Control Procedures \\
\hline $\begin{array}{l}\text { Product } \\
\text { design }\end{array}$ & $\begin{array}{l}\text { 1. Poor product } \\
\text { design }\end{array}$ & $\begin{array}{l}\text { Improved information about } \\
\text { effects of product design } \\
\text { changes on total costs; detailed } \\
\text { data about warranty and repair } \\
\text { cost }\end{array}$ \\
\hline $\begin{array}{l}\text { Planning } \\
\text { and } \\
\text { scheduling }\end{array}$ & $\begin{array}{l}\text { 2. Over or } \\
\text { underproduction } \\
\text { 3. Suboptimal } \\
\text { investment in } \\
\text { fixed assets }\end{array}$ & $\begin{array}{l}\text { Accurate production planning } \\
\text { systems; proper approval of } \\
\text { production orders. } \\
\text { Review and approval of fixed } \\
\text { asset transactions; budgetary } \\
\text { controls. }\end{array}$ \\
\hline $\begin{array}{l}\text { Production } \\
\text { operations }\end{array}$ & 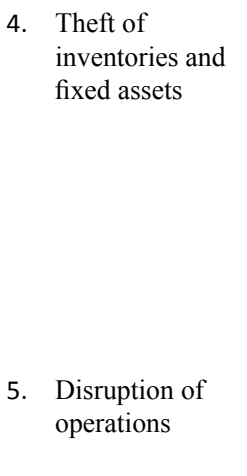 & $\begin{array}{l}\text { Restricted physical access to } \\
\text { work in process and finished } \\
\text { goods inventories and to fixed } \\
\text { assets; documenting all materials } \\
\text { movements; identification and } \\
\text { tracking of all fixed assets; } \\
\text { proper documentation and } \\
\text { review of all transactions } \\
\text { involving disposal of fixed } \\
\text { assets; adequate insurance } \\
\text { Backup power supplies; disaster } \\
\text { recovery plans; evaluation of } \\
\text { suppliers disaster preparedness }\end{array}$ \\
\hline $\begin{array}{l}\text { Cost } \\
\text { accounting }\end{array}$ & $\begin{array}{l}\text { 6. Inaccurate cost } \\
\text { data }\end{array}$ & $\begin{array}{l}\text { Data entry and processing } \\
\text { controls; use of barcode and } \\
\text { RFID technology where feasible; } \\
\text { periodic reconciliation of record } \\
\text { with physical counts }\end{array}$ \\
\hline $\begin{array}{l}\text { General } \\
\text { threats }\end{array}$ & $\begin{array}{ll}\text { 7. } & \begin{array}{l}\text { Loss, } \\
\text { alteration or } \\
\text { unauthorized } \\
\text { disclosure of } \\
\text { data }\end{array} \\
\text { 8. } & \begin{array}{l}\text { Poor } \\
\text { performance }\end{array}\end{array}$ & $\begin{array}{l}\text { Backup and disaster recovery } \\
\text { plans; logical and physical } \\
\text { access controls; configurationof } \\
\text { ERP systems to enforce } \\
\text { proper segregation of duties; } \\
\text { encryption; data transmission } \\
\text { control } \\
\text { Development and periodic } \\
\text { review of appropriate } \\
\text { performance reports }\end{array}$ \\
\hline
\end{tabular}

Sumber: Romney dan Steinbart (2007) 
Ada beberapa kerangka yang dijadikan acuan dalam control atau pengendalian, diantaranya untuk mengatasi ancaman tersebut:

1. COBIT (Control Objective for Information and Related Technology)

Dikembangkan pertama kali oleh Information System Audit and Control Association (ISACA) tahun 1992 yang kemudian dikelola oleh The IT Governance Institute (ITGI) yang merupakan sebuah badan afiliasi ISACA. COBIT merupakan kerangka pengendalian internal yang diterima secara umum untuk teknologi informasi (TI).

\section{COSO Internal Control Frameworks (COSO)}

Dikembangkan oleh The Committee of Sponsoring Organization (COSO) of the Treadway Commission sejak sebelum 1980 yang kemudian dikembangkan hingga kini. COSO Internal Control Framework lebih dikenal sebagai acuan yang diterima umum dalam pengendalian internal perusahaan dan kaitannya dengan pelaporan keuangan dan proses operasi.

3. COSO Enterprise Risk Management (ERM)

Merupakan kerangka pengendalian internal dan manajemen risiko yang dirancang COSO sebagai pengembangan dari kerangka sebelumnya, COSO Internal Control Framework. Perbedaan mendasar dari COSO adalah bahwa ERM mengintegrasikan keandalan kerangka pengendalian internal COSO ke arah penilaian dan pengelolaan risiko.

\section{Input Controls}

Tujuan dari input control (Cascarino, 2007) adalah untuk memastikan bahwa:

- Semua transaksi benar-benar terjadi dan tercatat dengan lengkap.
- Semua transaksi yang masuk dalam sistem telah lengkap dan akurat.

- Semua transaksi dimasukkan hanya satu kali.

\section{Database Controls}

Hal-hal penting dalam database control adalah (Weber, 2007):

- Database subsystem bertanggungjawab dalam hal defining, creating, modifying, deleting dan reading data dalam sistem informasi. Database subsystem memelihara data deklaratif, menghubungkan dengan aspekaspek statis dari objek nyata dan asosiasinya serta data prosedural, menghubungkan aspek-aspek dinamis dari objek nyata dan asosiasinya.

- Access control yang digunakan dalam database subsystem untuk mencegah akses yang tidak terotorisasi untuk menggunakan data. Dengan adanya kebijakan akses maka administrator memperhatikan aspek pengamanan data sehingga tidak dengan mudah diganti oleh database user.

- Di bawah kebijakan discretionary acces control, para user yang bukan pemilik data dapat melakukan akses terbatas dengan tipe akses sebagai berikut:

a. Name-dependent access control, yang mengijinkan atau mengabaikan akses untuk nama dalam data sumber.

b. Content-dependent access control, yang mengijinkan atau mengabaikan akses tergantung dari isi data.

c. Context-dependent restriction, yang mengijinkan atau mengabaikan akses tergantung dari konteksnya.

d. History-dependent access, yang mengijinkan atau mengabaikan akses berdasarkan histori dari akses database sebelumnya.

- Di bawah kebijakan mandatory access control, tingkatan klasifikasi dapat dibuat 
untuk mengkhususkan item data atau atribut dalam sebuah record atau relasi dan untuk record atau relasi secara bersamaan.

- Ketika program aplikasi menggunakan database, mereka harus mengikuti update yang benar dan melapor protocol untuk melindungi integritas database. Protocol update terdiri dari:

a. Melakukan cek secara berurutan file permintaan transaksi dan master file selama batch update.

b. Memastikan kebenaran dari prosedur end-of-file yang diikuti sehingga tidak kehilangan record.

c. Memproses transaksi yang bersifat multiple untuk single record dalam correct order.

d. Melakukan posting terhadap transaksi moneter yang memiliki ketidak-sesuaian antara master file record dengan suspense account.

- Protocol report terdiri dari:

a. Printing control data untuk tabel/standing data internal untuk memastikan bahwa isinya akurat dan lengkap.

b. Printing run-to-run control total.

c. Printing suspense account entries.

\section{Output Controls}

Tujuan dari pengendalian terhadap output adalah untuk (Cascarino, 2007):

- Memberikan jaminan bahwa hasil dari input dan processing benar-benar telah menjadi output.

- Output hanya dapat diberikan kepada orang yang mempunyai kewenangan.

\section{METODE PENELITIAN}

Dalam mencari solusi atas permasalahan yang dihadapi PT. Aseli Dagadu Djokdja, alat analisis yang digunakan untuk merancang desain sistem informasi produksi adalah dengan metode
FAST (Framework for the Application of System Thinking). Metode tersebut dikembangkan oleh Whitten (2007).

Tahapan-tahapan FAST meliputi scope definition, problemanalysis, requirementanalysis, logical design, decision analysis, physical design and integration, construction and testing, installation and delivery. Dalam penelitian dibatasi hanya sampai pada empat tahap pertama. Sedangkan untuk mendokumentasikan business requirement, digunakan use-case (Whitten, 2007).

Tahapan dalam metode FAST yang digunakan adalah:

1. Tahap Definisi Ruang Lingkup (Scope Definition Phase)

Tahap ini bertujuan untuk mengetahui seberapa besar manfaat dari pengembangan sistem yang akan dilakukan. Pada tahapan ini ditentukan juga batasan dari pengembangan sistem dengan terlebih dahulu melakukan identifikasi terhadap masalah, inisiatif, dan arahan yang merupakan pendorong adanya pengembangan sistem.

Tujuan dari tahap ini bukan untuk memecahkan permasalahan tetapi pengklasifikasian dan pengelompokan masalah.

2. Tahap Analisis Permasalahan (Problem Analysis Phase)

Pada tahap ini, dilakukan identifikasi secara mendalam atas pernyataan masalah yang dihasilkan dari tahapan pertama. Tujuan dari tahapan ini untuk mengetahui tujuan dari rencana pengembangan sistem yang mengacu pada masalah, kesempatan dan batasan.

Dalam tahap analisis masalah dibutuhkan dokumentasi sistem yang sedang berjalan atau yang dikenal juga dengan model bisnis (business model). Dokumentasi sistem berjalan digunakan untuk menganalisis ketidakefesienan, kemacetan sistem, atau masalah lain terkait dengan proses bisnis 
perusahaan. Notasi $\diamond$ (diamond) pada gambar 1 mengindikasikan bahwa tahap ini dibutuhkan checkpoint pada akhir tahapan.

3. Tahap Analisis Kebutuhan (Requirement Analysis Phase)

Tahap analisis kebutuhan merupakan tahapan kritikal dari rencana pengembangan sistem. Tujuannya adalah mengetahui apa yang menjadi kebutuhan utama dari sistem atas sistem baru yang akan dikembangkan. Pada tahap ini dibuat definisi dan prioritas kebutuhan end user secara bisnis bukan secara teknis.

4. Tahap Desain Logis (Logical Design Phase)

Bisnis proses dari suatu sistem akan dikembangkan dan ditelaah lebih jauh dengan menggunakan logical model pada tahap desain logis. Logical model merepresentasikan sistem secara keseluruhan dan komprehensif. Model sistem yang dihasilkan dari tahap ini dirancang untuk menggambarkan struktur data, proses bisnis, arus data dan interface.

Untuk memberikan gambaran yang lebih jelas mengenai metode analisis yang digunakan, diilustrasikan dalam Gambar 1

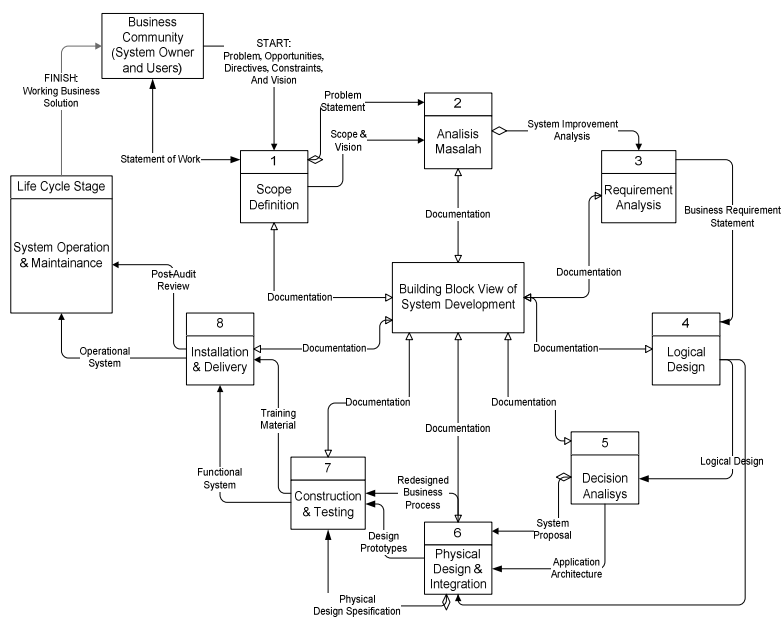

Sumber: Bentley \& Whitten (2007) Gambar 1

Fase Pembangunan Sistem Metode FAST

\section{HASIL PENELITIAN DAN PEMBAHASAN}

\section{Tahap Definisi Ruang Lingkup (Scope Definition Phase)}

\subsection{Identifikasi Produk}

Produk yang dihasilkan PT. Aseli Dagadu Djokdja dapat dikelompokkan berdasarkan jenisnya yaitu:

a. Produk Cloth (Pakaian), meliputi: oblong, polo shirt, jaket, kaos ladies, jumper.

b. Produk Non Cloth, meliputi:

- Produk Aksesoris misalnya topi, pin, tas, slayer.

- Produk Stationer misalnya ballpoint, map, seminar kit, pensil, paper clip, agenda, block note.

- Produk Household meliputi mug, gelas, tatakan gelas, payung, jam dinding.

\subsection{Identifikasi Proses Bisnis}

Dalam satu siklus produksi, proses yang dilakukan oleh PT. Aseli Dagadu Djokdja adalah:

a. Order, merupakan proses di mana konsumen memesan produk.

b. Desain produk, merupakan proses di mana para tim kreatif menterjemahkan keinginan konsumen ke dalam bentuk desain grafis.

c. Pengadaan bahan, merupakan proses di mana bagian purchasing melakukan proses pengadaan bahan sesuai dengan spesifikasi yang diinginkan oleh konsumen.

d. Proses produksi cloth, merupakan proses di mana pesanan berbahan dasar kain diolah dari bahan baku menjadi WIP1 untuk bahan potongan, WIP2 untuk kain yang telah disablon atau dibordir, WIP3 untuk barang yang telah dijahit.

e. Proses produksi non cloth, merupakan proses di mana purchasing melakukan pemesanan barang non cloth kepada supplier barang non cloth

f. Pengepakan, merupakan proses di mana semua produk yang selesai diproduksi, 
disortir untuk yang terakhir kali, dilengkapi dengan tag dan barcode, serta di-packing.

g. Warehousing, merupakan proses di mana seluruh barang yang disimpan di dalam gudang (bahan baku, WIP 1, WIP2, WIP3, WIP3 non cloth, finished goods) harus melalui proses quality control. Di dalam proses ini menghasilkan barang cacat berupa scrap, rework dan spoiled.

h. Layanan Konsumen, merupakan aktivitas yang bersifat memberikan pelayanan kepada konsumen. Layanan Konsumen ini terdiri dari pengiriman pesanan, penanganan komplain dan entertain kepada konsumen.

i. Support, merupakan integrasi dari seluruh kegiatan manajemen dalam operasi bisnisnya, yang meliputi seluruh kegiatan yang bersifat administratif serta pengadaan berbagai fasilitas yang mendukung kegiatan bisnis.

\subsection{Analisis Aktivitas}

Untuk mempermudah dalam melakukan analisis terhadap aktivitas produksi di PT. Aseli Dagadu Djokdja, maka dilakukan proses pengelompokan aktivitas menjadi pool-pool tertentu, yaitu:

1. Pool Aktivitas Order, meliputi kegiatan:

- Aplikasi penawaran, yaitu mengirimkan penawaran kepada para calon konsumen.

- Aplikasi order, yaitu aktivitas di mana konsumen melakukan order.

- Pembatalan order, yaitu aktivitas di mana konsumen membatalkan order yang telah dilakukan karena alasan tertentu.

2. Pool Aktivitas Desain Produk, meliputi kegiatan:

- Initial design, yaitu menterjemahkan keinginan klien ke dalam bahasa gambar.

- persetujuan desain, yaitu aktivitas di mana pihak manajemen memberikan rencana desain kepada konsumen kemudian konsumen menyampaikan persetujuannya.
- pisah warna, yaitu aktivitas yang dilakukan oleh desainer untuk memisahkan warna yang ada dalam desain ke dalam prosentase CMYK.

- Proofing, yaitu aktivitas di mana manajemen membuatkan sampel produk jadi untuk disampaikan kepada konsumen.

3. Pool Aktivitas Pengadaan Bahan, meliputi kegiatan:

- order bahan ke supplier (untuk pesanan yang bahan bakunya tidak tersedia di gudang).

- pembelian bahan, yaitu aktivitas di mana Kepala Bagian Purchasing melakukan pembelian bahan apabila bahan baku yang dibutuhkan tidak tersedia di gudang.

- Permintaan bahan ke gudang, yaitu aktivitas di mana manajer PPIC mengajukan permintaan bahan ke gudang, untuk membuat produk sesuai pesanan.

4. Pool Aktivitas Produksi cloth meliputi kegiatan:

- membuat film, yaitu mengaplikasikan desain yang sudah dipisah warna ke dalam kertas film.

- proses mal (pemolaan), yaitu pembuatan pola produk memotong bahan sesuai dengan pola.

- bordir/sablon, yaitu proses pengaplikasian desain ke produk melalui teknik sablon atau bordir.

- Jahit, yaitu proses menjahit bahan yang sudah disablon atau dibordir.

5. Pool Aktivitas Produksi non cloth meliputi kegiatan:

- Order ke supplier non cloth, yaitu proses memesan produk non cloth ke supplier.

- Pembelian barang, yaitu proses pembelian barang non cloth.

6. Pool Aktivitas Pengepakan, meliputi:

- Finishing, yaitu proses pemasangan barcode dan tag ke produk yang telah selesai diproduksi. 
- Pengepakan, yaitu proses pembungkusan barang yang sudah di-barcode dan dipasang tag secara satuan ke dalam plastik kemasan.

7. Pool Aktivitas Warehousing, meliputi:

- QC, yaitu proses pengecekan standar barang sebelum disimpan di gudang agar sesuai dengan spesifikasi yang telah ditetapkan oleh manajemen.

- Penyimpanan, merupakan proses penyimpanan semua barang berupa bahan baku, WIP dan barang jadi.

8. Pool Aktivitas Layanan Konsumen, meliputi:

- pengiriman produk, yaitu proses pengiriman produk yang telah jadi ke alamat konsumen.

- Penanganan komplain, yaitu biaya yang dikeluarkan untuk menangani dan menindaklanjuti komplain.

- Entertainment, yaitu aktivitas jamuan tamu.

9. Pool Aktivitas Support, meliputi:

- Administrasi pusat, yaitu aktivitas yang bersifat umum dan dikonsumsi oleh semua departemen.

- Maintenance, merupakan aktivitas menjaga dan memelihara agar aktiva yang dimiliki menjadi awet.

- Depresiasi, merupakan aktivitas pengalokasian biaya aktiva tetap yang dikonsumsi bersama.

\subsection{Penelusuran Biaya ke Aktivitas Penggeraknya (Cost Driver)}

Setelah semua aktivitas dan biaya dirinci, selanjutnya biaya-biaya tersebut dianalisis mana saja yang terkait dengan proses produksi kemudian dikelompokkan sesuai dengan pool aktivitasnya untuk dicari cost driver yang memicu timbulnya biaya tersebut. Hasil penelusuran biaya ke cost driver dapat dilihat dalam tabel 4.
Tabel 4

Pool Activity - Cost Driver

\begin{tabular}{|c|c|c|}
\hline Pool Activity & Cost & Candidate Cost Driver \\
\hline $\begin{array}{l}\text { Pool Aktivitas } \\
\text { Order }\end{array}$ & $\begin{array}{l}\text { - Biaya } \\
\text { Telekomunikasi } \\
\text { - Biaya Pos dan Paket } \\
\text { - Biaya Gaji } \\
\text { Marketing } \\
\text { - Biaya Bonus/ THR/ } \\
\text { Insentif }\end{array}$ & $\begin{array}{l}\text { - Call Duration } \\
\text { - Jumlah Penawaran } \\
\text { - Jam Kerja } \\
\text { - Jam Kerja }\end{array}$ \\
\hline $\begin{array}{l}\text { Pool Aktivitas } \\
\text { Desain } \\
\text { Produk }\end{array}$ & - Biaya Gaji & - Jam Kerja \\
\hline $\begin{array}{l}\text { Pool Aktivitas } \\
\text { Pengadaan } \\
\text { Bahan }\end{array}$ & $\begin{array}{l}\text { - Biaya Gaji } \\
\text { - Biaya } \\
\text { Telekomunikasi }\end{array}$ & $\begin{array}{l}\text { - Jam Kerja } \\
\text { - Call Duration }\end{array}$ \\
\hline $\begin{array}{l}\text { Pool Aktivitas } \\
\text { Produksi cloth }\end{array}$ & $\begin{array}{l}\text { - } \text { Biaya Gaji } \\
\text { - Biaya } \\
\text { Telekomunikasi }\end{array}$ & $\begin{array}{l}\text { - Jam Kerja } \\
\text { - Call Duration }\end{array}$ \\
\hline $\begin{array}{l}\text { Pool Aktivitas } \\
\text { Produksi non } \\
\text { cloth }\end{array}$ & $\begin{array}{l}\text { - } \text { Biaya Gaji } \\
\text { - Biaya } \\
\text { Telekomunikasi }\end{array}$ & $\begin{array}{l}\text { - Jam Kerja } \\
\text { - Call Duration }\end{array}$ \\
\hline $\begin{array}{l}\text { Pool Aktivitas } \\
\text { Pengepakan }\end{array}$ & - Biaya Gaji & - Jam Kerja \\
\hline $\begin{array}{l}\text { Pool Aktivitas } \\
\text { Warehousing }\end{array}$ & $\begin{array}{l}\text { - } \text { Biaya Gaji } \\
\text { - Biaya Sewa Gudang } \\
\text { Mall } \\
\text { - Biaya Sewa }\end{array}$ & $\begin{array}{l}\text { - Jam Kerja } \\
\text { - Luas Lantai } \\
\text { - Luas Lantai }\end{array}$ \\
\hline $\begin{array}{l}\text { Pool Aktivitas } \\
\text { Layanan } \\
\text { Konsumen }\end{array}$ & $\begin{array}{l}\text { - Biaya Pos, Paket } \\
\text { dan Kemasan }\end{array}$ & - Jumlah Order \\
\hline $\begin{array}{l}\text { Pool Aktivitas } \\
\text { Support }\end{array}$ & $\begin{array}{l}\text { - Biaya Listrik } \\
\text { - Biaya Air } \\
\text { - Biaya Reparasi dan } \\
\text { Pemeliharaan Aktiva } \\
\text { Tetap-Kendaraan } \\
\text { - Biaya Reparasi dan } \\
\text { Pemeliharaan Aktiva } \\
\text { Tetap-Mesin } \\
\text { - Biaya Reparasi dan } \\
\text { Pemeliharaan Aktiva } \\
\text { Tetap-Gedung } \\
\text { - Biaya Sewa Gedung } \\
\text { - Biaya Rumah } \\
\text { Tangga } \\
\text { - Biaya Penyusutan } \\
\text { Aktiva Tetap } \\
\text { - Biaya Asuransi } \\
\text { - PBB }\end{array}$ & $\begin{array}{l}\text { - Kilowatt Hour } \\
\text { - Meter Kubik } \\
\text { - Kilometer } \\
\text { - Jam Mesin } \\
\text { - Umur Hari } \\
\text { - Luas Lantai } \\
\text { - Jumlah Karyawan } \\
\text { - Luas Lantai } \\
\text { - Luas Lantai } \\
\text { - Luas Lantai }\end{array}$ \\
\hline
\end{tabular}

Sumber: observasi dan wawancara manajemen Industri manufaktur, 2015. 


\section{Tahap Analisis Permasalahan (Problem Analysis Phase)}

Pemodelan sisteminformasi produksipada industri manufaktur clothing didahului dengan pemodelan use-case business requirement. Usecase requirement merupakan pemodelan terhadap hasil wawancara murni. Use-case ini kemudian dianalisis untuk mengetahui hal-hal yang harus dipertahankan, ditambahkan, atau diperbaiki yang didokumentasikan ke dalam use-case analysis. Setelah proses analisis dengan menggunakan use-case, dibuat desain database berdasarkan hasil analisis tersebut. Proses selanjutnya adalah mendokumentasikan rancangan sistem informasi yang telah dibuat ke dalam use-case design.

\subsection{Identifikasi Business Requirements Use- Case}

Hasil identifikasi requirements usecase yang berkaitan dengan tugas utama actor, informasi yang dibutuhkan actor dari sistem, informasi yang disediakan actor untuk sistem, perlu tidaknya sistem menginformasikan kepada actor setiap perubahan atau kejadian yang terjadi, serta perlu tidaknya actor menginformasikan kepada sistem setiap perubahan atau kejadian yang terjadi, akan tersaji dalam contex diagram. Gambar 2 berikut ini adalah contex diagram yang menampilkan keterkaitan tersebut.

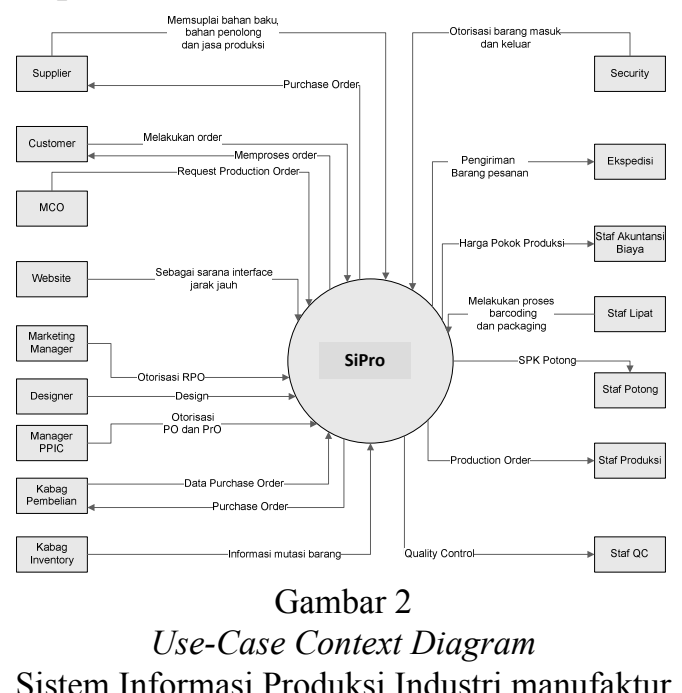

\section{Tahap Desain Logis (Logical Design Phase) 3.1 Dekomposisi Diagram}

Berikut adalah hasil dekomposisi Sistem Informasi Produksi

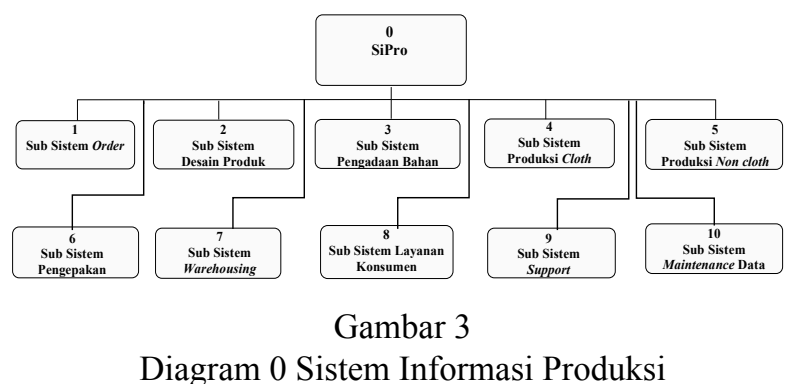

\subsection{Context Diagram}

Untuk memberikan ilustrasi mengenai hubungan antara SiPro dengan external entity, berikut ini digambarkan diagram konteks SiPro pada gambar 6 berikut:

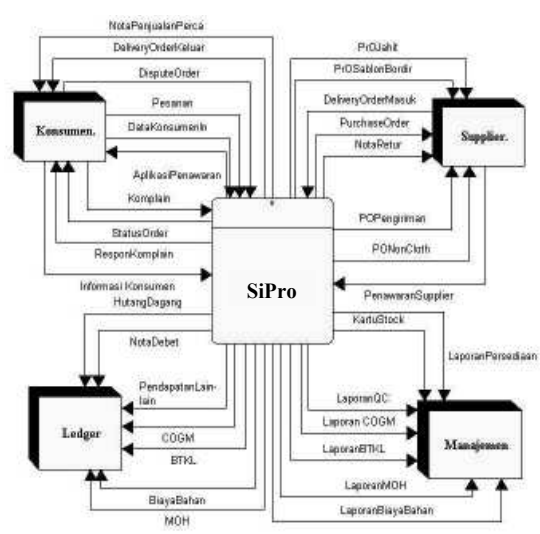

Gambar 4

Data Flow Context Diagram

Sistem Informasi Produksi

\subsection{Data Flow Diagram}

Untuk menggambarkan aliran data dan dokumen dalam Sistem Informasi Produksi ditampilkan data flow diagram pada masingmasing sub sistem. Gambar 7 merupakan gambar data flow diagram level 2. 


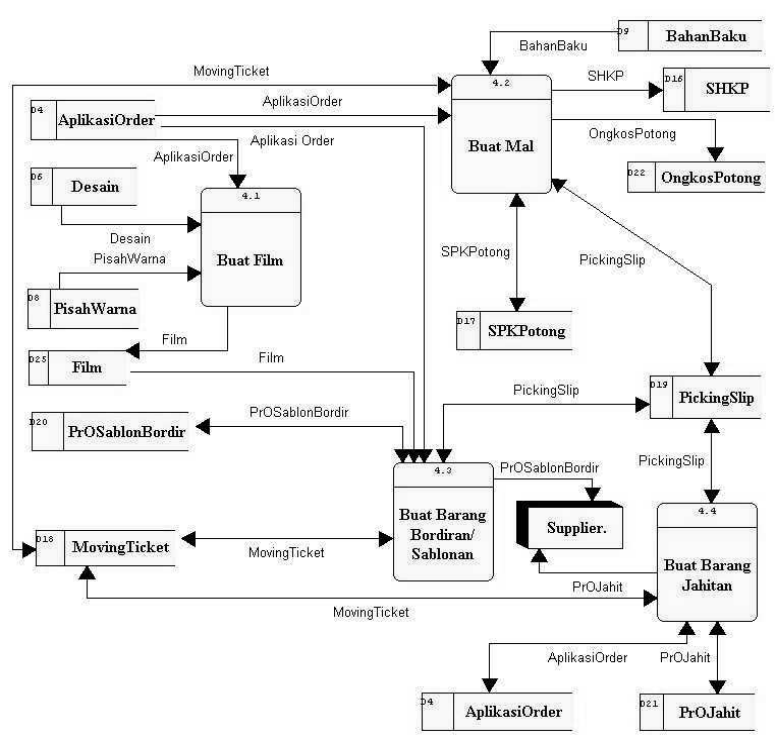

Gambar 5

Data Flow Diagram Level 2 Sub Sistem Produksi Cloth Sistem Informasi Produksi

\section{ABC System Entity dalam Sistem Informasi Produksi}

Untuk mengetahui entity yang menjadi sumberdatabagicostdriveragar dapatmenghitung tarif biaya akan dicerminkan dalam tabel 6. Kolom pool activity menunjukkan pembagian seluruh aktivitas produksi berdasarkan karakteristik kegiatan utamanya, kolom cost menunjukkan jenis biaya overhead, kolom candidate cost driver merupakan penggerak biaya dari masing-masing biaya overhead, sedangkan kolom cost driver entity source merupakan entitas yang memiliki informasi mengenai cost driver atau penggerak biaya overhead yang dimiliki oleh perusahaan. Angka yang terdapat di dalam tanda kurung pada kolom cost driver entity source merupakan nomor entity yang terdapat dalam data flow diagram.
Tabel 6

Cost Driver Entity Source

Sistem Informasi Produksi

\begin{tabular}{|c|c|c|c|}
\hline Pool Activity & Cost & $\begin{array}{c}\text { Candidate Cost } \\
\text { Driver }\end{array}$ & $\begin{array}{c}\text { Cost Driver Entity } \\
\text { Source (entity number) }\end{array}$ \\
\hline $\begin{array}{l}\text { Pool Aktivitas } \\
\text { Order }\end{array}$ & $\begin{array}{l}\text { - } \text { Biaya } \\
\text { Telekomunikasi } \\
\text { - Biaya Pos dan } \\
\text { Paket } \\
\text { - Biaya Gaji } \\
\text { Marketing } \\
\text { - Biaya Bonus/THR/ } \\
\text { Insentif }\end{array}$ & $\begin{array}{l}\text { - Call Duration } \\
\text { - Jumlah } \\
\text { Penawaran } \\
\text { - Jam Kerja } \\
\text { - Jam Kerja }\end{array}$ & $\begin{array}{l}\text { - Telepon (30) } \\
\text { - POPengiriman (26) } \\
\text { - Absensi (34) } \\
\text { - Absensi (34) }\end{array}$ \\
\hline $\begin{array}{l}\text { Pool Aktivitas } \\
\text { Desain Produk }\end{array}$ & - Biaya Gaji & - Jam Kerja & - Absensi (34) \\
\hline $\begin{array}{l}\text { Pool Aktivitas } \\
\text { Pengadaan Bahan }\end{array}$ & $\begin{array}{l}\text { - Biaya Gaji } \\
\text { - Biaya } \\
\text { Telekomunikasi }\end{array}$ & $\begin{array}{l}\text { - Jam Kerja } \\
\text { - Call Duration }\end{array}$ & $\begin{array}{l}\text { - Absensi (34) } \\
\text { - Telepon (30) }\end{array}$ \\
\hline $\begin{array}{l}\text { Pool Aktivitas } \\
\text { Produksi } \text { cloth }\end{array}$ & $\begin{array}{l}\text { - Biaya Gaji } \\
\text { - Biaya } \\
\text { Telekomunikasi }\end{array}$ & $\begin{array}{l}\text { - Jam Kerja } \\
\text { - Call Duration }\end{array}$ & $\begin{array}{l}\text { - Absensi (34) } \\
\text { - Telepon (30) }\end{array}$ \\
\hline $\begin{array}{l}\text { Pool Aktivitas } \\
\text { Produksi non } \\
\text { cloth }\end{array}$ & $\begin{array}{l}\text { - Biaya Gaji } \\
\text { - Biaya } \\
\text { Telekomunikasi }\end{array}$ & $\begin{array}{l}\text { - Jam Kerja } \\
\text { - Call Duration }\end{array}$ & $\begin{array}{l}\text { - Absensi (34) } \\
\text { - Telepon (30) }\end{array}$ \\
\hline $\begin{array}{l}\text { Pool Aktivitas } \\
\text { Pengepakan }\end{array}$ & - Biaya Gaji & - Jam Kerja & - Absensi (34) \\
\hline $\begin{array}{l}\text { Pool Aktivitas } \\
\text { Warehousing }\end{array}$ & $\begin{array}{l}\text { - Biaya Gaji } \\
\text { - Biaya Sewa } \\
\text { Gudang Mall } \\
\text { - Biaya Sewa }\end{array}$ & $\begin{array}{l}\text { - Jam Kerja } \\
\text { - Luas Lantai } \\
\text { - Luas Lantai }\end{array}$ & $\begin{array}{l}\text { - Absensi (34) } \\
\text { - Departemen (50) } \\
\text { - Departemen (50) }\end{array}$ \\
\hline $\begin{array}{l}\text { Pool Aktivitas } \\
\text { Layanan } \\
\text { Konsumen }\end{array}$ & $\begin{array}{l}\text { - Biaya Pos, Paket } \\
\text { dan Kemasan }\end{array}$ & - Jumlah Order & - AplikasiOrder (4) \\
\hline $\begin{array}{l}\text { Pool Aktivitas } \\
\text { Support }\end{array}$ & $\begin{array}{l}\text { - Biaya Reparasi } \\
\text { dan Pemeliharaan } \\
\text { Aktiva Tetap- } \\
\text { Gedung } \\
\text { - Biaya Sewa } \\
\text { Gedung } \\
\text { - Biaya Rumah } \\
\text { Tangga } \\
\text { - Biaya Penyusutan } \\
\text { Aktiva Tetap } \\
\text { - Biaya Asuransi } \\
\text { - PBB }\end{array}$ & $\begin{array}{l}\text { - Kilowatt Hour } \\
\text { - Meter Kubik } \\
\text { - Kilometer } \\
\text { - Jam Mesin } \\
\text { - Umur Hari } \\
\text { - Luas Lantai } \\
\text { - Jumlah } \\
\quad \text { Karyawan } \\
\text { - Luas Lantai } \\
\text { - Luas Lantai } \\
\text { - Luas Lantai }\end{array}$ & $\begin{array}{l}\text { - Departemen (50) } \\
\text { - Ledger } \\
\text { - Kendaraan (51) } \\
\text { - Mesin (53) } \\
\text { - Gedung (52) } \\
\text { - Departemen (50) } \\
\text { - Karyawan (31) } \\
\text { - Departemen (50) } \\
\text { - Departemen (50) } \\
\text { - Departemen (50) }\end{array}$ \\
\hline
\end{tabular}

\section{KESIMPULAN DAN SARAN}

\section{Kesimpulan}

Penghitungan tarif cost driver yang semakin detil akan menghasilkan informasi biaya manufaktur yang semakin akurat. Ketepatan dalam melakukan pooling biaya dan pemilihan 
cost driver akan mempengaruhi kualitas informasi yang dihasilkan. Perancangan sistem informasi produksi untuk menghasilkan output berupa COGS (Cost of Goods Manufactured) dengan pendekatan $A B C$ System akan melibatkan berbagai siklus di luar siklus produksi sehingga akurasi tarif cost driver semakin tinggi.

\section{Saran}

Rancangan yang dibuat bersifat generik, apabila ingin diterapkan maka perlu melakukan analisis mendalam terhadap pengamanan data. Rancangan ini tidak berlaku untuk semua jenis industri manufaktur karena setiap industri manufaktur memiliki keunikan tersendiri. Jika ingin menerapkannya perlu melakukan pengkajian terhadap siklus bisnis dan cost drivernya.

\section{DAFTAR PUSTAKA}

Bentley, Lonnie D \& Jeffrey L. Whitten. System Analysis \& Design for Global Enterprise, Seventh Edition. McGraw Hill: New York. 2007.

Cascarino, Richard. Auditor's Giude to Information System Auditing. United State of America: John Willey \& Sons. Inc., 2007.

Connoly, T and C. Begg. Database System: A Practical Approach to Design Implementation and Management, $3^{\text {rd }}$ Ed. Addison Wesley. 2002
Hansen, Don R. And Maryanne M. Mowen. Management Accounting, $7^{\text {th }}$ Ed. Thomson-Southwestern. 2005.

Hongren, Charles T., Srikant M, Datar, and George Foster. Cost Accounting A Management Emphasis, 12th Ed. Prentice Hall International ED. 2006.

IEEE, 2000, IEEE Std 1061-1998 - Standar for Software Quality Metrics Methodology, The Institute of Electrical and electronics Engineers, New York, US, 1998.

ISACA. 2007. IS Standards, Guidelines and Procedures for Auditing and Control Profesionals. Information System Audit and Control Association. February 2007.

ITGI. COBIT 4.1. The IT Governance Institute. Rolling Meadow, IL. 2007.

Jogiyanto, Hartono. Analisis dan Desain Sistem Informasi: Pendekatan Terstruktur Teori dan Praktek Aplikasi Bisnis. Andi Yogyakarta. 2005

Kendall, E. Kenneth and Julie E-Kendall. System Analysis and Design International Edition $5^{\text {th }}$ Ed. Prentice-Hall Inc. 2002

Mulyadi, Akuntansi Biaya Edisi 5. Salemba Empat. 1999.

Romney, Marshall and Paul Steinbart. Accounting Information System, Eleventh Edition. Pearson Education, Inc. 2008

Weber, Ron. Information System Control and Audit, Prentice-Hall Inc. 1999 